\title{
Todo el poder a la asamblea: cuerpo, autonomía y dictadura en el Estado español*
}

\author{
All the power to the assembly: body, autonomy and dictatorship in the Spanish State
}

Todo o poder para a assembléia: corpo, autonomia e ditadura no Estado espanhol

Inés Molina Agudo**

Facultad de Filosofía y Letras, Universidad Autónoma de Madrid, España

Correo electrónico: inmolinesca@gmail.com

Sergio Vega Jiménez***

Facultad de Filosofía, Universidad Complutense de Madrid, España

Correo electrónico: vegasergio.94@gmail.com

Revista Corpo-grafías: Estudios críticos de y desde los cuerpos / Volumen 5 - Número 5 / enero - diciembre de 2018 / ISSN impreso 2390-0288, ISSN digital 2590-9398 / Bogotá, D.C., Colombia / pp. 58-69.

Fecha de recepción: 25 de mayo de 2017

Fecha de aceptación: 9 de julio de 2017

Doi: https://doi.org/10.14483/25909398.14206

Cómo citar este artículo: Molina, I. Vega, S. (2018, enero-diciembre). Todo el poder a la asamblea: cuerpo, autonomía y dictadura en el Estado español. Revista Corpo-grafías: Estudios críticos de y desde los cuerpos, 5(5), pp. 58-69/ ISSN 2390-0288.

*Artículo de investigación: Este artículo ha sido elaborado a partir de la experiencia desarrollada en el proyecto curatorial ASAMBLEA, fruto de los seminarios que impartió el profesor, Juan Albarrán Diego en el máster de Ha del Arte Contemporáneo y Cultura Visual que acoge el Museo Nacional Centro de Arte Reina Sofía (Madrid), titulados “Del performance art a los performance studies", entre los meses de octubre y diciembre de 2017.

**Graduada en Historia del Arte por la Universidad Complutense de Madrid, máster en Historia del Arte Contemporáneo (MNCARS/UAM/UCM) cuenta con una beca de fomento a la investigación en la Universidad Autónoma de Madrid. Sus líneas de investigación oscilan entre los análisis visuales y performativos de los movimientos sociales durante la Transición española, y la reflexión en torno a la memoria histórica en aquellos territorios marcados por el yugo de dictaduras.

***Graduado en Filosofía por la Universidad Complutense de Madrid y cursa el máster de Estudios Avanzados en Filosofía en esta misma institución. Ha sido miembro activo de la asociación estudiantil y colectivo de investigación militante La Caverna. Contó con una beca de colaboración en el Departamento de Filosofía y Sociedad en la Facultad de Filosofía UCM durante el año 2017. Sus líneas de investigación se centran en las transformaciones en el mundo del trabajo, el neoliberalismo y la relación entre los cuerpos y el poder.

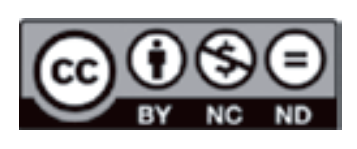




\section{Resumen}

Este artículo es elaborado a partir del trabajo realizado en los seminarios que impartió el profesor Juan Albarrán en el seno del máster de Ha del Arte Contemporáneo y Cultura Visual, acogido por el Museo Nacional Centro de Arte Reina Sofía (Madrid), titulados "Del performance art a los performance studies", entre los meses de octubre y diciembre de 2017. En él se moviliza la concepción del cuerpo en la filosofía butleriana para pensar el asambleísmo y la resistencia civil en los últimos años de la dictadura franquista, tomando como caso de estudio cuatro acciones políticas y asociativas comprendidas entre 1976 y 1979. Los problemas desplegados se enlazarán con el concepto de surrogate performance (performance suplente) formulado por Philip Auslander, para esbozar los usos políticos del registro fotográfico de estas asambleas y su orientación hacia una tarea de politización de la memoria.

Palabras clave: asambleísmo; autonomía; cuerpo relacional; Franquismo; performatividad.

\section{Abstract}

This article has been prepared based on the work carried out in the seminars taught by Professor Juan Albarrán in the master's degree in Contemporary Art and Visual Culture, hosted by the Reina Sofía National Museum (Madrid), entitled "From performance art to performance studies", between October and December 2017. In this text, the conception of the body in Judith Butler's philosophy is mobilized to think about the assembly and the civil resistance in the last years of the Franco's dictatorship, taking into consideration four political and associative actions developed between 1976 and 1979. The problems displayed will be connected with the concept of surrogate performance formulated by Philip Auslander to outline the political uses of the photographic record of these assemblies and their orientation to a task of politicizing memory.

Keywords: assemblyism; autonomy; relational body; Francoism; performativity.

\section{Resumo}

Este artigo foi elaborado a partir do trabalho realizado nos seminários realizados pelo professor Juan Albarrán no seio do mestrado de História da Arte Contemporânea e Cultura Visual, acolhido pelo Museo Nacional Centro de Arte Reina Sofia (Madrid), intitulados "Del performance art a los perfomance studies" ("Da performance art aos performance studies"), entre os meses de Outubro e Dezembro de 2017. Neste mobiliza-se a concepção do corpo na filosofia butleriana para pensar o assembleísmo e a resistência civil nos últimos anos da ditadura franquista, tomando como caso de estudo quatro ações políticas e associativas compreendidas entre 1976 e 1979. Os problemas exibidos ligar-se-ão com o conceito de surrogate performance (performance suplente) formulado por Philip Auslander para esboçar os usos políticos do registro fotográfico destas assembleias e a sua orientação para uma tarefa de politização da memória.

Palavras-chave: assembleísmo; autonomia; corpo relacional; Franquismo; performatividade. 
Este artículo emerge como reflexión crítica y teórica a partir de la experiencia desarrollada en el proyecto curatorial $A S A M B L E A^{1}$, fruto de los seminarios que impartió el profesor Juan Albarrán Diego entre los meses de octubre y diciembre de 2017, en el máster de Ha del Arte Contemporáneo y Cultura Visual que acoge el Museo Nacional Centro de Arte Reina Sofía (Madrid), titulados "Del performance art a los performance studies". ASAMBLEA, buscaba explorar la creciente disidencia social en la década final del franquismo a partir de la recopilación de documentación visual de distintas asambleas y encuentros clandestinos -la huelga de la fábrica de Roca (1976), las Jornadas Libertarias de Barcelona (1977), la construcción colectiva de una casa en la barriada madrileña de Orcasitas (1977) y las II Jornadas Estatales de la Mujer (1979) -, explorando el paisaje y el enmarañamiento de los cuerpos entonces acontecido. Finalmente, $A S A M B L E A$ se concretó en un artefacto que adoptó el formato de libro y, rehuyendo las definiciones normativas de fanzine, revista o dossier, se presentó como dispositivo historiográfico, en tanto que conjunto sistemático de elementos heterogéneos. En él, se reunieron un puñado de fotografías y algunos textos que buscaban activar la cualidad performativa de la memoria impresa en estos documentos, imbricándose de esta forma en la estela de trabajos que buscan recuperar el recuerdo y las genealogías de lucha en el Estado español, ahogadas por el silencio de la dictadura franquista.

En este artículo, buscamos relocalizar el cuerpo -entidad-masa vulnerable, demarcada en el espacio y el tiempo, limitada en sus tejidos, sus fluidos, sus porosidades, sus relaciones orgánicas internas y externas- en el convulso paisaje histórico del último Franquismo. Para ello, trenzaremos nuestras reflexiones con las epistemologías relacionales y corporales de Judith Butler y los feminismos que han pensado la corporalidad como matriz de la acción social -Iris Marion Young, Mari Luz Esteban-, que nos permitirán analizar las redes que sostienen las prácticas y las culturas militantes. El objetivo será iluminar la necesidad de llevar a cabo una historiografía que cuide y piense la pulsión caliente de los cuerpos que se mueven, se oponen, luchan y resisten en el seno de los regímenes dictatoriales, y esbozar una apuesta metodológica que ponga el cuerpo en el centro.

En la primera parte del artículo se explorarán las distintas apuestas teóricas que ubican los cuerpos en el seno de las luchas sociales, incidiendo especialmente en algunos de los conceptos de la filosofía de Judith Butler como vulnerabilidad, resistencia o dependencia, y que hacen aparecer un cuerpo relacional en el horizonte teórico. En la segunda parte, estos conceptos serán aplicados al terreno específico de la disidencia social en la última década de la dictadura franquista, tomando como referencia una de las asambleas celebradas durante la huelga general de los trabajadores de Roca (1976). Por último, se esbozarán algunas claves de lectura que permiten vincular el ejercicio de la memoria histórica con la performatividad emanada de la documentación de estos acontecimientos, por cuanto el dispositivo historiográfico de $A S A M B L E A$ abría un espacio donde el objeto se presentaba en el contexto de lo táctil.

\section{Aquel cuerpo que resiste: vulnerabilidad y resistencia en Judith Butler}

En esta breve reflexión sobre la ambivalente relación entre cuerpo, espacio y movimientos sociales al final de la dictadura española, quisiéramos plantear una aplicación de las filosofías del cuerpo y de la teoría de la performatividad, a la fotografía y a la historiografía como dispositivos orientados a la politización de la memoria. Asimismo, la performatividad butleriana y la concepción del cuerpo relacional nos permiten plantear un conjunto de prácticas militantes desde abajo que no se entienden completamente sin una consideración sobre las redes que sostienen a los cuerpos en lucha. El concepto de cuerpo relacional que la filosofía de Judith Butler propone, permite doblar su

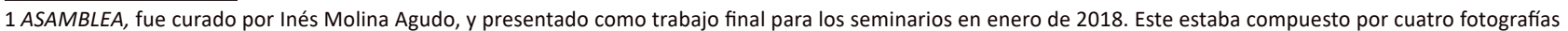
móviles y manipulables -registro fotográfico de los cuatro momentos asociativos ya mencionados-y cuatro textos descriptivos, así como un ensayo inicial donde se abocetaban algunas de las ideas que hoy exponemos de forma más extensa en este artículo, relativas a la performatividad desarrollada en el ejercicio asambleario, el papel del registro fotográfico en la activación de la memoria y la importancia de atender a la resistencia de los cuerpos en lucha durante el último Franquismo. 
concepto de resistencia en política de la movilidad corporal (2017, pp.74-130) Cuestionar los espacios legítimos, desestabilizar los cauces de los movimientos permitidos o desafiar al poder dictatorial con encuentros insospechados, es lo que los distintos movimientos sociales estaban realizando en los estertores de la dictadura.

Los feminismos que han centrado su mirada en el cuerpo (Esteban, 2011, Hernando, 2012) plantean que la incorporación de las estructuras delimita un campo de acciones posibles, una función clave para la reproducción de las relaciones de dominación que, no obstante, deja resquicios para la reconfiguración de estas, situando toda posibilidad de transformación en una subversión de lo posible que arraiga en el cuerpo. Antropólogas como Mari Luz Esteban, plantean la necesidad de seguir pensando la teoría feminista y la práctica política desde el cuerpo, planteándolo no sólo como soporte de las dominaciones sino también como aquello que eminentemente somos y, por tanto, como la base para ser de otra forma, un "cuerpo-agente", que resiste, subvierte y se transforma, ampliando el campo de sus posibilidades (2011, p. 48).

El tipo de contextualismo que Butler pone en juego, intenta dar cuenta de la importancia de los trasfondos del sujeto y de su radical opacidad. Al insertar al sujeto en un contexto relacional, propone una mirada atenta a las condiciones infraestructurales de posibilidad del sujeto político y del espacio público, pudiendo ser esta una herramienta fructífera para la historiografía de las dictaduras y sus resistencias. Por tanto, proponemos tomar los conceptos de vulnerabilidad y resistencia que subyacen a la corporalidad relacional como una mirada renovada a las luchas antifranquistas, dado que ese abordaje relacional se pone al servicio de una disputa por el espacio y por su habitabilidad.

En los últimos años, Butler ha incidido especialmente en las condiciones infraestructurales del sostenimiento de las vidas. A menudo, parte de la idea de cuerpo que opera en las movilizaciones que ponen al descubierto el apoyo que requieren los cuerpos para comparecer en el espacio público. Butler plantea que está teniendo lugar una resistencia corporal plural, en la que las demandas exponen la precarización de las condiciones de subsistencia de los cuerpos.

Los cuerpos, al exponerse en la calle y mostrar su precariedad, también están resistiendo a los poderes, están escenificando una forma de resistencia que presupone un tipo específico de vulnerabilidad y que se opone a la precariedad. En el emplazamiento de esos cuerpos, y en su reivindicación, se "presupone que el espacio público es algo dado, que ya existe y se le reconoce como tal" (Butler, 2017, p. 74). Esa congregación de cuerpos pone en cuestión la habitual separación entre público y privado, tan cara a la histórica exclusión de las mujeres de la política (Posada, 2015). Esa veta crítica que une las redes que nos sostienen con la disputa por el espacio, es la que recorre la autora al pensar la vulnerabilidad como el catalizador de la resistencia política o de la subversión ética de un conjunto de normas que nos violentan.

La manera en que Butler piensa la performatividad es también un cuestionamiento de las maneras en que los otros nos afectan, estrechamente ligada la interdependencia de los cuerpos. El sujeto solo es autónomo parcialmente, por ser al mismo tiempo dependiente, por la imposibilidad de pensar la propia vida con independencia de otras vidas. En este planteamiento, la libertad queda asociada a la dependencia misma, al encuentro emplazado de los cuerpos para la discusión pública y la demanda de lo que les es negado, lo cual se traduce en "una lucha en torno a los modos básicos sobre los que, como cuerpos, nos sostenemos en el mundo, una lucha contra la privatización de derechos, la invisibilización y el abandono" (Butler, 2012). Se pone el acento, ante lógicas desposesivas - del capital o de cualquier poder dictatorial-en las condiciones de sostenibilidad de los cuerpos. Por consiguiente, la política se entiende también como la disputa que genera el espacio de aparición, un espacio que se crea a través de la acción plural, que siempre requiere apoyo de algún tipo porque es corporal. En ese emplazamiento del cuerpo se cifra su apertura, no siendo enteramente nuestro porque siempre está volcado a un afuera: 
Aunque luchemos por los derechos sobre nuestros propios cuerpos, los cuerpos por los que luchamos nunca son lo suficientemente nuestros. El cuerpo tiene una dimensión invariablemente pública. Constituido en la esfera pública como un fenómeno social, mi cuerpo es y no es mío. Entregado desde el comienzo al mundo de los otros, el cuerpo Ileva sus huellas, está formado en el crisol de la vida social (Butler, 2004, p. 52).

La exposición interdependiente de los cuerpos, que es desafío y demanda, así como ejecución inmediata del espacio que se desea habitar, se entiende como oposición a un marco normativo, cuando este producen violencia, no ofrece reconocimiento o deviene anacrónico (Butler, 2005). En consecuencia, lo que se intente delimitar como espacio público y normativo, comporta erigir marcos de reconocimiento que hagan que esas vidas expuestas cuenten como vidas, reconociendo ineludiblemente sus condiciones de dependencia, que son también las condiciones para comparecer en el espacio público sin violencia.

Resulta del mayor interés rehabilitar las potencialidades de las ideas expuestas en el marco de un ejercicio de politización de la memoria, en el que se atiende a un mismo tiempo a los cuerpos implicados en los casos de estudio y a la implicación corporal de quienes aborden unas imágenes mediante las cuales se les interpela, activando procesos de politización. De esta manera, el carácter extático de los cuerpos en relación deviene conexión intertemporal.

\section{Cincuenta, cien, mil personas reunidas: los cuerpos disidentes en la dictadura franquista}

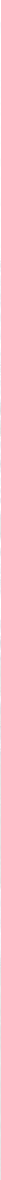


Un hombre, de espalda, cabello espeso -joven- se dirige a unas quinientas personas. Personas de gesto grave, severo, con los brazos cruzados, que escuchan, ejercen la reflexión y manifiestan preocupación. Se encuentran en una nave industrial, junto a otros más de mil quinientos cuerpos que la fotografía ha truncado a la posteridad (Imagen 1). Es el año 1976; los ventanales, abiertos, y las mangas de camisa, nos sitúan en el mes de septiembre. El otoño apenas está despuntando y la lucha también.

Se trata de una de las asambleas que darán forma a la larga huelga de la fábrica de Roca Radiadores (enclavada entre los pueblos de Gavà y Viladecans, en la región catalana del Baix Llobregat) que se prologará durante 96 días (entre noviembre de 1976 y febrero de 1977). Ese verano, los obreros de Roca Radiadores habían comenzado a debatir la posibilidad de romper los enlaces sindicales: durante el último enfrentamiento con la empresa, tutelado por Comisiones Obreras, lucharon por la negociación del convenio colectivo, desembocando en un rotundo fracaso ${ }^{2}$.

Las dos mil personas presentes en la nave, exigen a Roca una subida de los salarios, la reducción de la jornada laboral a cuarenta horas, la escolaridad de sus hijos y la amnistía de los despedidos. Allí reunidas, las dos mil personas ejercen sus derechos, sin preguntar, sin pedir permiso: el derecho a la reunión, la libertad de expresión, el derecho a la manifestación y a la huelga. La asamblea, esa reunión de cuerpos que deliberan, es comprendida por los allí presentes como el único órgano de poder soberano, una herramienta para la lucha obrera; y los delegados, elegidos por los trabajadores y revocables en cualquier momento, son sencillamente los representantes de la voluntad de la mayoría.

Mientras que las demás fábricas del Baix Llobregat siguen obedientemente las directrices de Comisiones Obreras, entonces articuladas en torno al reciente reformismo sostenido por el Partido Socialista Unificado de Cataluña (PSUC) y el Partido Comunista Español (PCE) ${ }^{3}$, la de Roca se materializa como una lucha incómoda, autónoma, que viene a desmantelar los planes de los sindicatos en la región. En el contexto de la formación del nuevo Estado posfranquista -a finales de año se aprueba la Ley para la Reforma Política, y a principios de 1977 la legalización de los partidos y sindicatos-, los trabajadores de Roca destapan la hipocresía del reformismo y se enfrentan con sus cuerpos al régimen que se reconfigura con un nuevo rostro.

Cuando el país deviene cárcel, las tentaciones de fuga se multiplican, pero también los encuentros entre los cuerpos. La potencia de la asociación fruto de una praxis militante compartida se torna desafío y proclama: es el final de los cuerpos dóciles. En la España de los años setenta, asistimos a un encumbramiento de una práctica asambleísta radical, que acontece en los distintos espacios de vida, performando una democracia popular encarnada en la reunión. Tal y como señala Judith Butler,

2 Un relato documentado y contrastado de la huelga de Roca puede encontrarse en el texto de Alonso Quiñones, A. (2008). La huelga de Roca, autoorganización contra el pacto social. En Espai en blanc (Ed.), Luchas autónomas de los años 70 (pp. 137-160). Madrid: Traficantes de sueños. La huelga de Roca es también explorada en la película Autonomía obrera, de Orsini Zegrí y Falconetti Peña (España, 2008), donde se recogen los testimonios de algunos de los participantes.

3 Es importante destacar el papel que jugaron los partidos y los sindicatos de signo antifranquista durante la Transición democrática española, sumándose a la firma de los Pactos de la Moncloa en el año 1977, compuestos por dos acuerdos distintos: el Acuerdo sobre el programa de saneamiento y reforma de la economía y el Acuerdo sobre el programa de actuación jurídica y política. Ambos acuerdos buscaban establecer un programa político y económico que preparase al Estado español para competir en el mercado global, adecuando un sistema democrático capitalista-procedimental análogo al de los países vecinos. Las organizaciones políticas y sindicales opositoras al régimen se convierten en agentes desmovilizadores durante este proceso, ya que leen la conflictividad social como un elemento desestabilizador para la consecución de un pacto de Estado entre las fuerzas opositoras y las fuerzas del régimen. Para conocer la deriva de las distintas izquierdas españolas ante esta coyuntura, Molinero, C., Ysás, P. (2016). De la hegemonía a la autodestrucción: El Partido Comunista de España (1956-1982). Barcelona: Crítica; Molinero, C., Ysás, P. (2008). Els anys del PSUC: el partir de l'antifranquisme (1956-1981). Barcelona: L'Avenç; Molinero, C., Ysás, P. (Coords.) (2010). Construint la ciutat democràtica: El moviment veïnal durant el tardofranquisme y la transició. Barcelona: Icaria. 
(...) la acción conjunta de los cuerpos, en el contexto de una lucha, una reivindicación o una comunicación pública, siempre implica un ejercicio de performatividad construido en plural. En el cuerpo se inscribe una fuerza referencial avasalladora que, una vez se alía con otros cuerpos, llega a la zona visible (2017, p.15).

En el contexto estas acciones corporeizadas guardan un significante común: su autonomía. Frente a un rígido entramado de burocracia, intereses y élites dominantes en un régimen en descomposición, este pueblo autonombrado se desviste de jerarquías y estructuras, para dar paso a otra manera de construir lo político. La asamblea, desnuda, independiente de cualquier organización o sindicato, se convierte en el instrumento esencial, pre-político, de los movimientos populares. Emerge entonces el "cuerpo vibrátil” (Rolnik, 2006), hasta entonces anestesiado por el disciplinamiento que impone el régimen franquista asociado a una suerte de fordismo ibérico; un cuerpo que reconoce por fin su vulnerabilidad y se deja afectar por la alteridad del mundo: se desencadena entonces una "vida pública" densa y sustantiva, puesto que la realidad política se construirá permanentemente a partir de las tensiones que protagonizan los cuerpos en alianza, los cuerpos organizados que aparecen en el espacio público. Serán estos cuerpos disidentes, que rompen con las estructuras representativas y biopolíticas de la dictadura, los que encarnen el sujeto de ruptura del régimen franquista.

En los años setenta, este pueblo auto-organizado en asambleas despliega batallas y conflictos en cada resquicio de las ciudades, cuyo control era incapaz de asumir cualquier agente del espectro institucional-estatal del momento (ni los sindicatos, ni el Partido Comunista Español, emblema histórico de la resistencia antifranquista; ni siquiera las Comisiones Obreras, recientemente adheridas al proyecto reformista encabezado por Manuel Fraga (ribarne ${ }^{4}$ ). Frente al crecimiento exponencial de los conflictos, el régimen lleva a cabo un ingente esfuerzo de recomposición que cristaliza en una nueva configuración del Estado español, consolidada con la firma de los Pactos de la Moncloa en 1977 y, un año más tarde, con la aprobación de la Constitución española ${ }^{5}$. A partir de la aparente restitución del sistema democrático, una vez se legalizan y se encauzan institucionalmente las luchas hasta el momento desarrolladas -en definitiva, una vez perdida la autonomía-, los cuerpos se desmovilizarán.

\section{La memoria encarnada: las fotografías de asambleas}

En ASAMBLEA se recogieron las fotografías de cuatro momentos de esta performatividad plural desarrollada en los años setenta en el Estado español, constituyendo una auténtica puesta en el centro de los cuerpos disidentes que buscan y construyen reconocimiento, redistribución, justicia. Se trata de experiencias heterogéneas, que quieren abrir frente a la persona que sostuviera estos documentos en sus manos un breve muestrario del ciclo de luchas desarrollado en la década: una asamblea en una fábrica catalana (Imagen 1), el estriptis público de tres travestis durante un concierto en Barcelona (Imagen 2), la construcción colectiva de una casa en la barriada madrileña de Orcasitas (Imagen 3) y un debate público durante el segundo encuentro feminista estatal celebrado en Granada (Imagen 4).

\footnotetext{
4 Consciente de la pronta caducidad del régimen, el ministro franquista, Manuel Fraga Iribarne (1922-2012) encabeza el conocido como proyecto de reforma política del franquismo durante la Transición española, que aboga por la adecuación del sistema político español a las demandas del escenario capitalista global.

5 La Constitución española, aprobada en referéndum el 6 de diciembre de 1978, marca en los relatos oficiales la culminación del proceso de Transición democrática española, estableciendo la monarquía parlamentaria como forma de gobierno y cediendo la jefatura del Estado al rey Juan Carlos I de España. Para una aproximación crítica al proceso constitucional: Bueno, J. M. (2017). Llamamiento a un proceso constituyente. Barcelona: Icaria; Rodríguez, E. (2010). Por qué fracasó la democracia en España. La Transición y el régimen del '78. Madrid: Traficantes de Sueños; Morán, G. (2015). El precio de la transición. Madrid: Akal.
} 


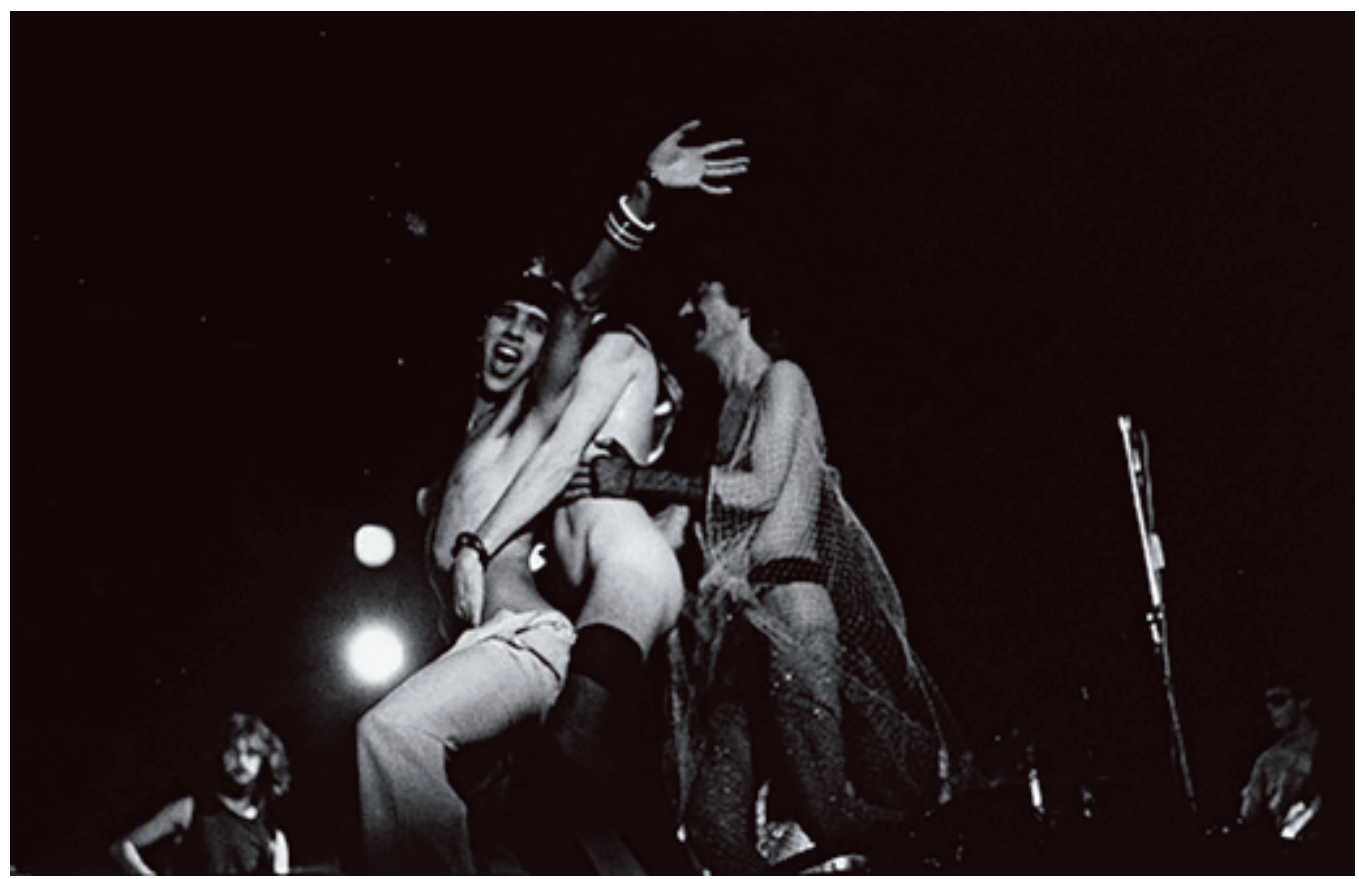

Imagen 2. Performance de los artistas Camilo, Ocaña y Nazario durante las Jornadas Libertarias de Barcelona (1977)

Fotografia: Eduard Omedes

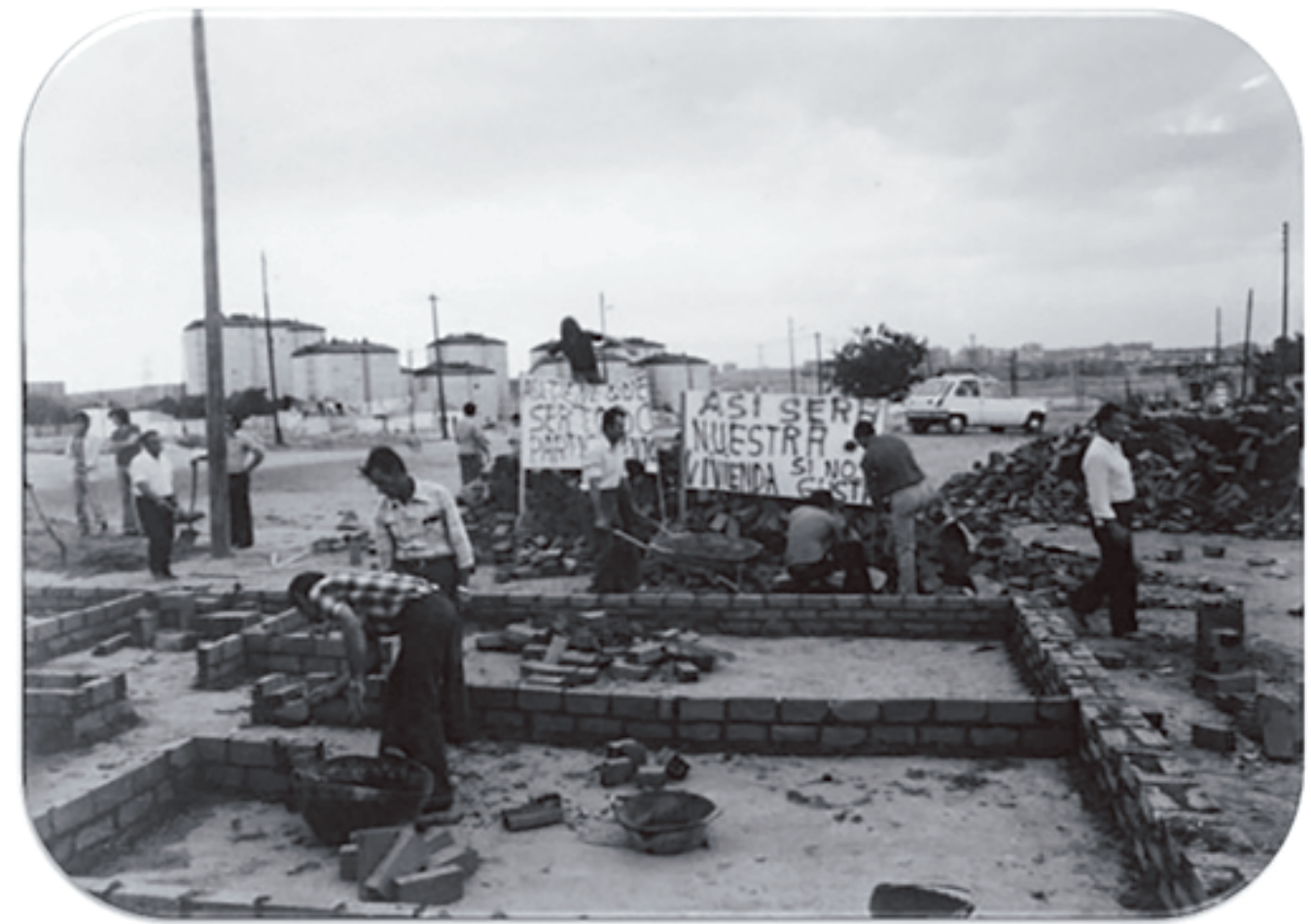

Imagen 3. Construcción colectiva de una casa en la barriada madrileña de Orcasitas, al hilo del proceso de denuncia del plan de expropiación territorial impulsado por la terrateniente María Orcasitas (1975) Fotografía: Archivo Asociación de Vecinos de Orcasitas 
Imagen 4. Asamblea durante las II Jornadas Estatales de la Mujer (Granada, 1979) Fotografía: Archivo Asamblea de Mujeres de Granada (AMG)

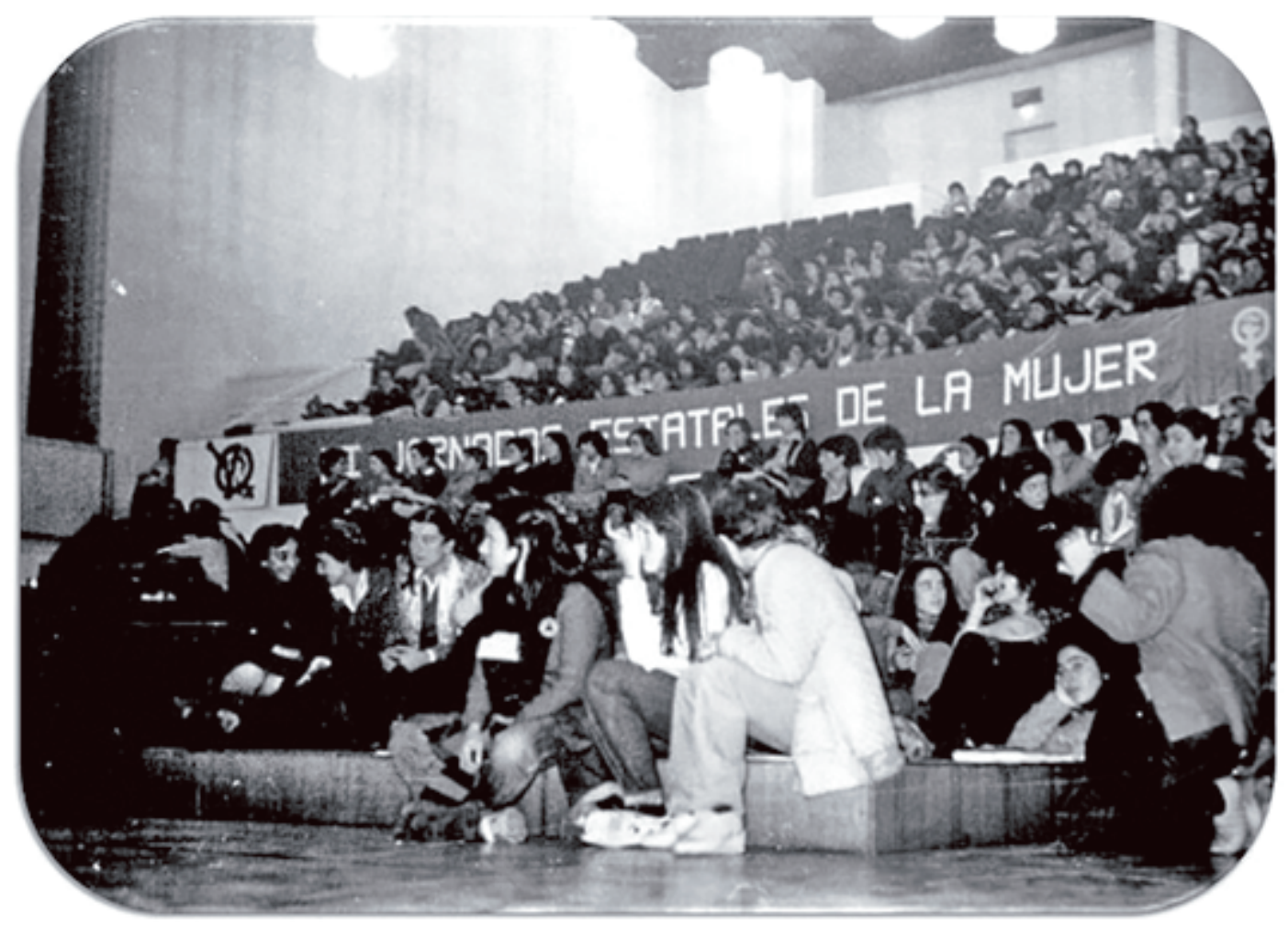

Una performatividad plural que guarda una intrínseca dimensión estética, en tanto que implica la transformación sensible de todas las personas implicadas en esta movilización de lo político, así como la constitución de una nueva realidad que no se fundamenta en interpretaciones, sino en la experiencia de sus afectos y efectos (Fischer-Lichte, 2011). Una performatividad que se contagia y se transmite a la documentación de los acontecimientos, tal y como ha explorado Philip Auslander en sus textos, a quien asigna el concepto de "performance suplente" (surrogate performance), poniendo de relieve la cualidad fenomenológica del registro de estas acciones (2014).

A propósito de la memoria impresa en los documentos históricos, Hannah Arendt señalaba:

Considerados en su mundanidad, acción, discurso y pensamiento tienen mucho más en común que cualquiera de ellos con el trabajo o la labor. No «producen», no engendran (bring forth) nada, son tan fútiles como la propia vida. Para convertirse en cosas mundanas, es decir, en actos, hechos, acontecimientos y modelos de pensamientos o ideas, lo primero de todo han de ser vistos, oídos, recordados y luego transformados (reified) en cosas, en rima poética, en página escrita o libro impreso, en cuadro o escultura, en todas las clases de registros (records), documentos y monumentos. Todo el mundo real de los asuntos humanos depende para su realidad y continuada existencia en primer lugar de la presencia de otros que han visto, oído y que recordarán y, luego, de la transformación de lo intangible en la tangibilidad de las cosas (Arendt, 1993, pp. 108-109). 
En ASAMBLEA, se pretendió recoger ambos sentidos de la performatividad: por un lado, lo performativo como acción/acontecimiento que excede la demanda implícita encerrada en la reunión de unos cuerpos en un mismo espacio; por el otro, la presentación de los registros de estas acciones/acontecimientos como documentos performativos en sí mismos. El fin último, por tanto, quiere recuperar lo que Santiago López-Petit denomina "memoria política", que quiere contraponerse a la manida Memoria Histórica6: una movilización de nuestros recuerdos desde el presente en aras de la consecución de otra realidad, aquella que se destila de la movilización y la lucha política, de una democracia sustantiva que nos ponga en el centro, y que bebe de las experiencias del pasado.

Creemos que las experiencias recogidas ejemplifican especialmente la condición relacional de los cuerpos, en el sentido de que la libertad de estos no se entiende sin tomar en cuenta su dependencia de relaciones no elegidas, de redes que les anteceden y los sostienen. Ahí opera una imbricación de libertad y necesidad que impugna la disociación en que suele incurrir el pensamiento político, así como una tradición de pensamiento -la occidental- poco dada a conferir algún tipo de dignidad al cuerpo, largamente ocultado y aún hoy misterio opacado por una razón desencarnada. En esta línea, pensar la performatividad del cuerpo político permite plantear la materialidad de los actores sociales, esto es, situar sus demandas en su vulnerabilidad y sufrimiento. Los cuerpos que se congregan para democratizar su espacio de trabajo o para construir casas a sus vecinos, ponen en juego un predicamento plural de demanda y necesidad, una subversión orientada a poner el foco en las necesidades corporales, la vulnerabilidad, los cuidados y la vida en común. En esa protesta, el cuerpo:

(...) no es sólo una entidad discreta con límites fijos, sino una serie de relaciones con la comida, la vivienda, la sexualidad, la apariencia, la movilidad, la audibilidad y la visualidad. Y esto está incorporado o desincorporado de un conjunto de relaciones sociales y formas institucionales que determinan en parte si una vida corporal va a persistir (Butler, 2014, p. 63).

Que las vidas puedan persistir o, mejor dicho, ser vividas y no sobrevividas, es algo que en un contexto dictatorial no depende totalmente del impulso de estas redes, ya que siempre estarán sujetas al arbitrio de una violencia estatal, de un poder que se graba a fuego en los cuerpos. Por ello, toda tarea de historización de las disidencias, que guarde además registro fotográfico, tiene ante sí la posibilidad de practicar un montaje dialéctico que desate la potencia visual de esas imágenes, disparando procesos de politización de la memoria. Una tarea, no obstante, nunca caduca, por cuanto los monstruos de la dictadura parecen no terminar de irse, prolongando la agonía de la posdictadura.

En estas condiciones, ¿qué función tienen los dispositivos historiográficos que, como ASAMBLEA, nos tocan y nos exigen implicación corporal, fugando hacia una politización de la memoria? En sus fotografías móviles, táctiles, ASAMBLEA demuestra que todo hacer ver es un hacer aparecer, y que el material impreso y manipulable se torna un "hacer sensible".

Al mismo tiempo, ¿qué relación tenemos con las imágenes que nos sobreviven en la historia del yugo dictatorial? Quizá podamos pensar, con George Didi-Huberman, que, en definitiva, ante una imagen, lo frágil seamos nosotros, y por eso la politización de la memoria es siempre una tarea a recomenzar (1997, p.12). La imagen, que perdura en el tiempo, sobrevive a la persona: las imágenes que hoy miramos y aprehendemos nos conectan con la temporalidad que nos antecede, con un pasado que grita porque el presente sigue socavando aquello que asfixiaba la resistencia y la disidencia de los que vinieron antes.

6 En el año 2007, el gobierno del Partido Socialista aprueba la Ley de Memoria Histórica y emprende trabajos de recuperación de la memoria en tiempos de dictadura que, sin embargo, se revela enormemente reificada y resemantizada por el poder, alumbrando relatos autoritarios que seguían camuflando verdades veladas con el fin de salvaguardar el papel que jugaron las instituciones y las organizaciones políticas durante la Transición (Delgado, 2009). 


\section{Conclusión}

En este artículo se ha tratado de llamar la atención sobre la centralidad de la dimensión corporal de las luchas en un contexto dictatorial, así como sobre los efectos performativos que su registro fotográfico desencadena, contribuyendo a una función de politización de la memoria.

A partir de la concepción del cuerpo en la filosofía de Judith Butler, hemos pensado el fenómeno del asambleísmo y la resistencia civil en los últimos años de la dictadura franquista. Hemos retomando la propuesta butleriana que entiende la movilización política como agrupación en torno a la precariedad que nos une y la vulnerabilidad que nos constituye, y la hemos insertado en un contexto históricopolítico concreto: los últimos años de la dictadura franquista y los primeros de la Transición democrática española (1975-1979).

Articulando nuestras reflexiones en torno al proyecto curatorial ASAMBLEA, se han esbozado una serie de claves de lectura que, poniendo los cuerpos disidentes en el centro, permiten pensar la represión en el seno de las dictaduras, así como la historia de sus resistencias. Retomando el concepto de surrogate performance formulado por Philip Auslander, se ha pensado la cualidad performativa de los registros fotográficos de las asambleas en la época, y se han enlazado con la problemática de la memoria en el contexto posfranquista.

En la medida en que las transiciones democráticas procedimentales, en los contextos posdictatoriales, todavía imprimen la huella del olvido, la tarea de politizar la memoria se revela urgente. En ella se inscribe el esfuerzo por pensar nuevos dispositivos y aproximaciones historiográficas, comprometidos con la construcción y reconstrucción de las genealogías de lucha sedimentadas sobre los territorios. 


\section{Referencias}

Alonso Quiñones, A. (2008). “La huelga de Roca, autoorganización contra el pacto social”. En Espai en blanc (Ed.), Luchas autónomas de los años 70 (pp. 137-160). Madrid: Traficantes de sueños.

Arendt, H. (1993). La condición humana. Barcelona: Paidós.

Asamblea de Mujeres de Granada. (2009). Jornadas Feministas Estatales de Granada treinta años después. Madrid: Federación de Organizaciones feministas.

Autonomía obrera (Orsini Zegrí y Falconetti Peña, España, 2008).

Auslander, P. (2014). "Surrogate Performances. Performance, Documentation and the New York Avant-Garde ca. 1964-1974". En E. Carpenter (Ed), On Performativy. Minneapolis: Walker Art Center.

Butler, J. (2017). Cuerpos aliados y lucha política. Hacia una teoría performativa de la asamblea. Barcelona: Paidós Básica.

Butler, J. (2005). Dar cuenta de sí mismo: violencia ética y responsabilidad. Buenos Aires: Amorrortu.

Butler, J. (2004). Vida precaria. El poder del duelo y la violencia. Barcelona: Paidós.

Butler, J. (2014). “Nosotros, el pueblo: apuntes sobre la libertad de reunión”. En VV.AA., ¿Qué es un pueblo? (pp. 47-67). Buenos Aires: Eterna Cadencia.

Butler, J. (2014). Repensar la vulnerabilidad y la resistencia. Recuperado el 14 de marzo de 2018, de https://es.scribd.com/ document/231310994/Judith-Butler-Repensar-La-Vulnerabilidad-y-La-Resistencia-Conferencia-en-La-Universidad-de-Alcala Butler, J. (2012). Cuerpos en alianza y la política de la calle. Recuperado el 8 de marzo de 2018, de http://www.trasversales.net/t26jb. htm

Delgado, L.E. (2009). “La nación invertebrada y la crisis de la normalidad democrática”. Estudios Culturales Iberoamericanos. 6(1), 215-234.

Denche, C., Alguacil, J. (1986). Orcasitas: “Del barro al barrio". Alfoz: Madrid, territorio, economía y sociedad. 34, 15-34.

Esteban, M. L. (2011). Cuerpos y políticas feministas. El feminismo como cuerpo. En Villalba Augusto, C.,

Fischer Lichte, E. (2011). Estética de lo performativo. Madrid: Abada.

Harvey, D. (2003). Espacios de esperanza. Madrid: Alianza.

Hernando, A. (2012) La fantasía de la individualidad. Buenos Aires: Katz.

Ingala, E. (2017). "A living engagement with politics: entrevista con Judith Butler". Isegoría. Revista de filosofía moral y política. 56(16), 21-37.

Jornades Llibertàries Internacionals 1977 Barcelona. Parc Güell (Video-Nou/Servei de Vídeo Communitari, España, 1977). La ciudad es nuestra (Tino Calabuig, España 1975).

Rodríguez, E. (2015). Por qué fracasó la democracia en España. La Transición y el régimen del 78. Madrid: Traficantes de Sueños. Rolnik, S. (2006). Geopolítica del chuleo. Recuperado el 24 de diciembre de 2017, de http://eipcp.net/transversal/1106/rolnik/es Perona, A. J. (2017). La política como resistencia, la vulnerabilidad y algunos cabos sueltos. Isegoría. Revista de filosofía moral y política. 56(1-6), 89-108.

Posada, M. L. (2015). Filosofía, Crítica y (Re) Flexiones feministas. Madrid: Fundamentos.

Valcárcel, A. (2000) Rebeldes. Hacia la paridad. Madrid: Plaza y Janes. 